\title{
Pressure Simulation for Footstep Energy Harvesting Paver
}

\author{
Aneesh A. Chand \\ School of Engineering \& Physics \\ University of the South Pacific \\ Suva, Fiji \\ aneeshamitesh@gmail.com
}

Maurizio Cirrincione

School of Engineering \& Physics

University of the South Pacific

Suva, Fiji

maurizio.cirrincione@usp.ac.fj

\author{
Kushal A. Prasad \\ School of Engineering \& Physics \\ University of the South Pacific \\ Suva, Fiji \\ kushalaniketp@gmail.com
}

Kabir A. Mamun

School of Engineering \& Physics

University of the South Pacific

Suva, Fiji

kabir.mamun@usp.ac.fj

\author{
Shivneel Singh \\ School of Engineering \& Physics \\ University of the South Pacific \\ Suva, Fiji \\ shivneelsingh03@gmail.com \\ Sumesh Narayan \\ School of Engineering \& Physics \\ University of the South Pacific \\ Suva, Fiji \\ sumesh.narayan@usp.ac.fi
}

\author{
F. R. Islam \\ School of Science \& Engineering \\ University of Sunshine Coast \\ Queensland, Australia \\ fislam@usc.edu.au
}

\begin{abstract}
Amongst all the energy sources from human motion, footstep has the potential of producing electrical energy as an alternative source to non-conventional renewable energy. Researchers have shown that human footstep kinetic energy can be converted to electrical energy by devised mechanism for low power application such as powering lights, radio and charging phones. Eventually, a novel fluid based energy harvesting paver was developed and tested to contribute towards sustainable development. The paver uses mini hydro generators to produce energy as fluid is forced through these mini hydro generators upon human stepping. This paper presents the pressure simulation of fluid bag system when subjected to an applied human force and the quarter ellipsoid shaped proved to be the best performer which can produce upto $1.4 \mathrm{~J}$ per step. The pressure simulation provides a relation between pressure and output power.
\end{abstract}

Keywords-footstep, fluid bag, fluid based energy harvester, non-conventional renewable energy and pressure

\section{INTRODUCTION}

Electricity demand is rising proportionally with the world population and meeting this energy demand with renewable energy resources (RERs) is a concern for the policy makers. Even a small contribution with RERs can reduces the effects of climate change that poses threat to the sustainable future of the globe and thus a lot of effort is put on adopting RESs as alternative energy [1]. Recent research highlights various types of renewable energy technologies that are being used or developed and their limitations along with the challenges faced while implementing such technologies in developing countries [2-3]. One of the most efficient non-conventional renewable energy sources could be through human locomotion. Human footstep has the potential of producing electrical energy as an alternative source to non-conventional renewable energy as it has energy in kinetic and potential form[4-5]. Human locomotion energy harvesting system ranges from harvesting energy directly from human motion such as while walking to pavement energy harvesting from footsteps.

According to literature [6-11], the key mechanics to harvest footstep kinetic energy is through the use of piezoelectric, electrostatic, electromagnetic and magnetostrictive materials. In this context, the overall efficiency of existing method of harvesting footstep energy are remarkable along with its advantage and disadvantage as shown in Table I. However, Islam et al. [12], designed a novel fluid based energy harvesting paver that works on fluid flow to generate energy using a mini hydro generator. The concept employed in this research is shown in Fig. 1. As human walk, force is exerted by the falling footstep on the paver and the fluid bag resulting in an increase in pressure inside the fluid bag. Therefore, the pressure simulation and analysis of different size and types of fluid bag is the key importance in this research.

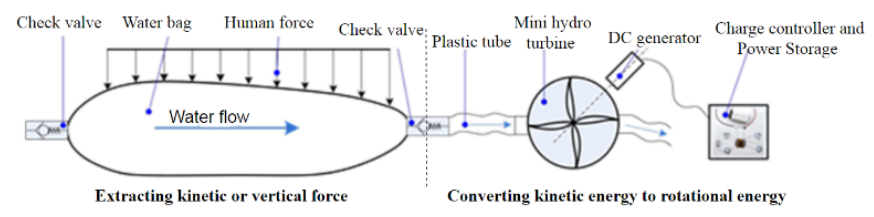

Fig. 1. System design of fluid based energy harvesting paver $[12,13]$.

However, based on the theory of pressure i.e. force over an area principle was used in designing the fluid bag. The pressure in the fluid bag is a critical component of this type of the energy harvesting system as human footstep exerted weight force over an area (fluid bag top surface) that creates pressure in the system. The pressure always decreases in a constant diameter pipe in the direction of the fluid flow with $\mathrm{p}=-\mathrm{dp} / \mathrm{dx}$. The pressure drop inside a pipe for a laminar flow is given by Equation 1: where $P_{1}$ and $P_{2}$ is the pressure at points 1 and 2 respectively, $\mu$ is the dynamic viscosity of the fluid (Pa.s), $L$ is the distance between two points of the pressure measurements $(\mathrm{m})$ and $V$ is the velocity of the fluid $(\mathrm{m} / \mathrm{s})[14]$.

$$
P_{1}+P_{2}=\frac{32 \mu L V}{d^{2}}
$$

The fluid bag material and design plays a significant role in efficient energy harvesting by this system. In this research paper pressure distribution simulation was carried out on several designs to optimise the fluid bag design which was lacking in the previous work. 
TABLE I. DIFFERENT TYPES OF FOOTSTEP ENERGY HARVESTING.

\begin{tabular}{|c|c|}
\hline Advantages & Disadvantages \\
\hline \multicolumn{2}{|c|}{ PaveGen [13] } \\
\hline $\begin{array}{ll}\text { - } & \text { Eco friendly } \\
\text { - } & \text { Uses recycled material in construction (rubber) } \\
\text { - } & \text { Commercially available } \\
\text { - } & \text { Good power output (5W from continuous footstep) }\end{array}$ & $\begin{array}{l}\text { - Not suitable for low population dense areas } \\
\text { - Possible ethical issue of harvesting energy without human / user consent } \\
\text { - Expensive }\end{array}$ \\
\hline \multicolumn{2}{|c|}{ Piezoelectric Tiles [6-8] } \\
\hline $\begin{array}{l}\text { - The piezoelectric transducers are small in size, so it's easy to vary the tile } \\
\text { size to meet the dimensional requirements. } \\
\text { - Clean energy with low maintenance } \\
\text { - Commercially available. }\end{array}$ & $\begin{array}{l}\text { - Not suitable for low population areas. } \\
\text { - Piezoelectric transducers are highly temperature sensitive } \\
\text { - The tiles have to be attached and fixed at one place which gives } \\
\text { exposure to weathering agents such as rain, wind and animals }\end{array}$ \\
\hline \multicolumn{2}{|c|}{ In-Shoe Energy Harvester [14] } \\
\hline $\begin{array}{l}\text { - } \text { Portable and Comfortable } \\
\text { - } \text { Does not required population dense areas as it can be worn by individuals } \\
\text { - Cheaper compared with other methods } \\
\text { - Sufficient power output to charge small electronics }\end{array}$ & $\begin{array}{l}\text { - Many factors have to be taken into account in the design phase such as } \\
\text { exposure to water /mud. }\end{array}$ \\
\hline \multicolumn{2}{|c|}{$\begin{array}{ll} & \text { Rack and Pinion [15] }\end{array}$} \\
\hline $\begin{array}{ll}\text { - } & \text { Eco friendly } \\
\text { - } & \text { Can store generated power in battery } \\
\text { - } & \text { Power generated just by walking on the system } \\
\text { - } & \text { Sufficient power output to charge small electronics }\end{array}$ & $\begin{array}{l}\text { - } \quad \text { Low power output when compared with conventional methods. } \\
\text { - } \quad \text { A greater depth of tile / step compression is needed when compared } \\
\text { with commercial mean. This may not be comfortable for the user. }\end{array}$ \\
\hline \multicolumn{2}{|c|}{ Fluid based power harvesting system / water circulation method [12] } \\
\hline $\begin{array}{l}\text { - Majority of the materials are locally available for construction } \\
\text { - Power generated can be stored. } \\
\text { - Eco friendly and clean energy generation } \\
\text { - Cheaper when compared with other methods }\end{array}$ & $\begin{array}{l}\text { - } \quad \text { Suitable for population dense areas } \\
\text { - } \quad \text { Requires maintenance since it has moving parts. }\end{array}$ \\
\hline
\end{tabular}

In Section II, the concept design and system integration is discussed. Section III, shows the ANSYS simulation results. Results and discussion are under section IV and conclusion are provide in Section V.

\section{CONCEPT DESIGN AND SYSTEM INTEGRATION}

Recent studies have shown that human locomotion induces a 500-1000 $\mathrm{N}$ dynamic force on the ground [18-19] and the time of exerted force by each step while walking is around 0.2 to 0.3 seconds [17]. The force that is generated by human footstep is wasted around the globe. In this context, a new concept of footstep energy harvesting technique is developed which uses the dynamic force as kinetic energy and converts it into electricity. The structural design of the paver is based on two tile structure, each consisting of a fluid bag connected with mini hydro generator and unidirectional valves.

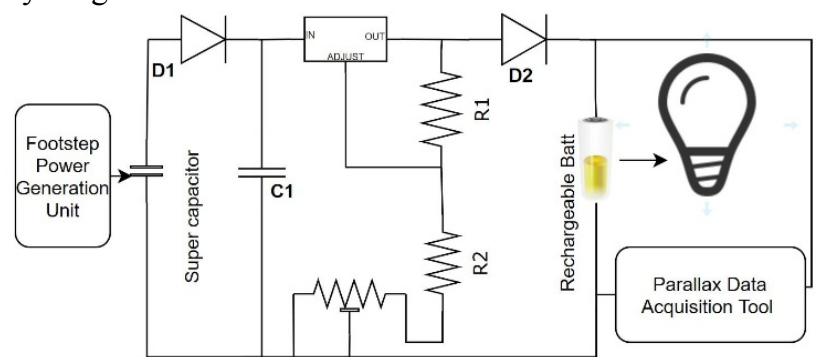

Fig. 2. Schematic representation of electrical model of the Fluid Based System Fluid Based System.

Particularly, the overall working principle can be abstracted as a graphical representation as shown in Fig. 3. The pavement architecture consist of super capacitor, charge control, battery and parallax data acquisition (DAQ) tool to capture the real time data as shown in Fig. 2. The harvested energy will be stored in a battery bank with the help of the super capacitor. The stored energy later can be used to power the low powered device as shown in Fig. 4.

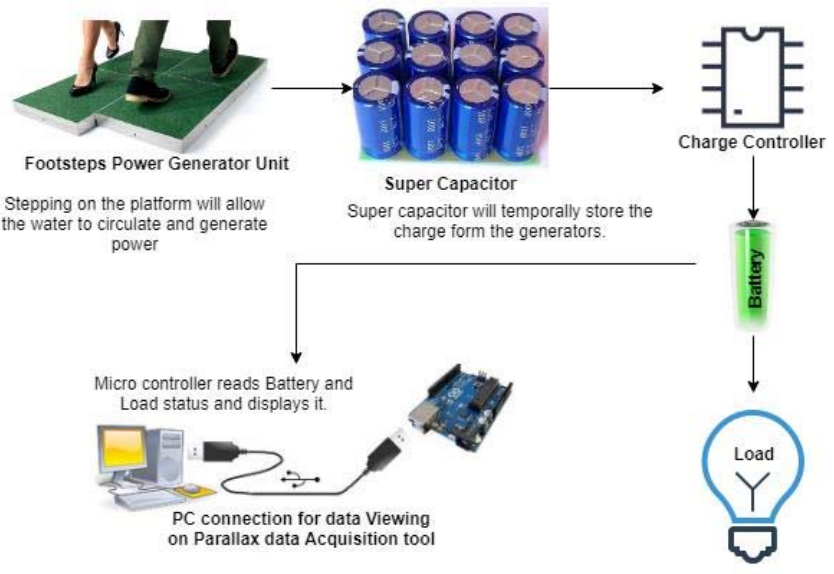

Fig. 3. Schematic representation of electrical model of the Fluid Based System.

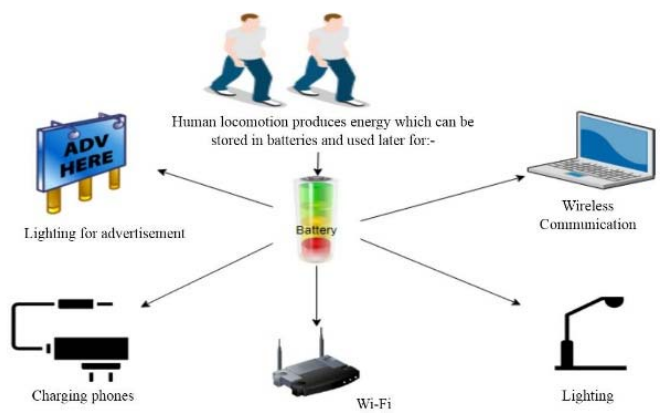

Fig. 4. Applications of the build based energy harvesting paver. 


\section{SimULATION}

The enclosed design and dimension of the mini hydro generator is shown in Fig. 5 and Fig. 6 respectively. ANSYS software was used to simulate the pressure distribution of the mini hydro generator turbine and paver fluid bag. The simulation was carried out to visualise the pressure behavior with different shapes of the bag and paver placement. The pressure simulation carried out in this research was using the mesh information for CFX analysis, the data for both foot to paver and paver to paver with Domain 1 and more parameters are available on the shared drive link [20].

- $\quad$ Nodes: ranges from 4162 to 3887

- Elements: ranges from 14986 to13831.

The pressure difference between the inlet and outlet of the mini hydro generator induces the driving torque for the turbine to rotate as shown in Fig. 7. Different size and design of bags were studied in this research and the simulation results for each case of the bag design is available on [21]. The summarised results is shown in Table II.

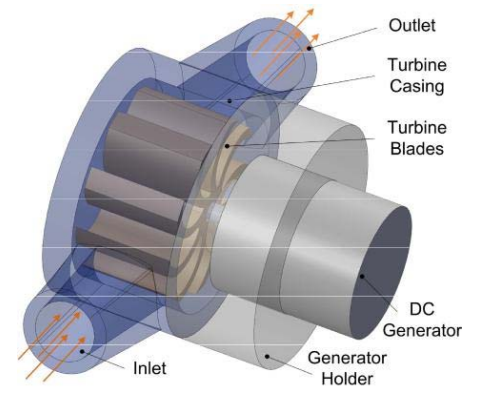

Fig. 5. Configuration of the enclosed radial-flow mini hydro generator [13].
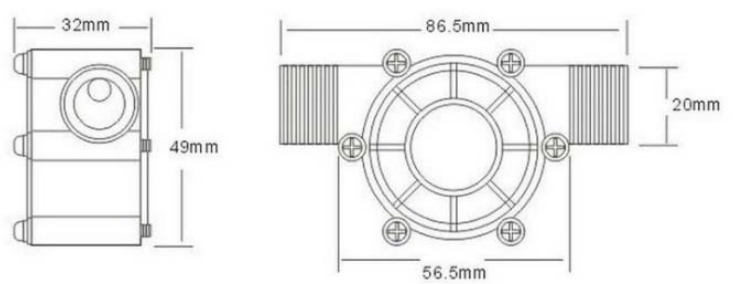

Fig. 6. 2-dimensional drawing of mini hydro generator.

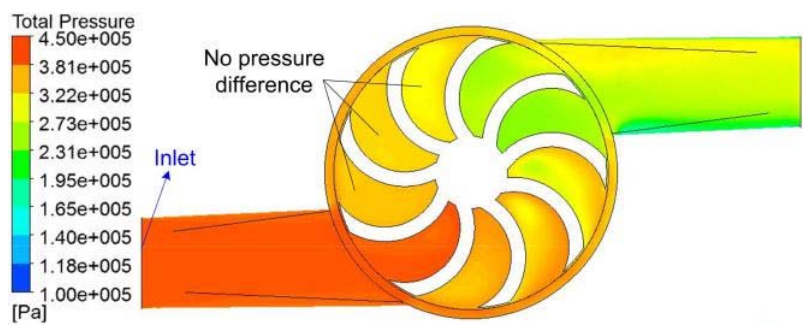

Fig. 7. Pressure distribution of mini hydro generator turbine blade [13].

The results obtained for pressure distribution contour are tabulated in Table II, the maximum pressure exerted on bag and paver placement are taken as for final design and fabrication. The power outputs are later discussed in Section IV.
TABLE II. Simulation Results of the Pressure CONTOUR

\begin{tabular}{lcc}
\hline & \multicolumn{2}{c}{ Pressure Contour (Pascal) } \\
\cline { 2 - 3 } Bag Shapes & Foot to Paver & Paver to Paver \\
\hline Square bag & $1.554 \times 10^{4}$ & 29.62 \\
Rectangular bag & $1.554 \times 10^{4}$ & 29.82 \\
Half Ellipse bag & $1.553 \times 10^{4}$ & 30.34 \\
Quarter Ellipsoid bag* & $7.609 \times 10^{3}$ & 29.17 \\
Semi-Circular bag & $1.554 \times 10^{4}$ & 29.5 \\
Vertically Cut Cylinder bag & $1.567 \times 10^{4}$ & 30.34 \\
\hline
\end{tabular}

\section{RESUlTS AND DISCUSSION}

To design a fluid based energy harvesting paver, pressure is one of the fundamental part for analysis. Table II shows the pressure results for both cases, Fig. 8 and Fig. 9 depict the maximum pressure obtained by Quarter Ellipsoid bag. Foot to bag and paver to paver pressure values are $7.609 \times 10^{3} \mathrm{~Pa}$ and 29.17 Pa, respectively for the Quarter Ellipsoid bag.

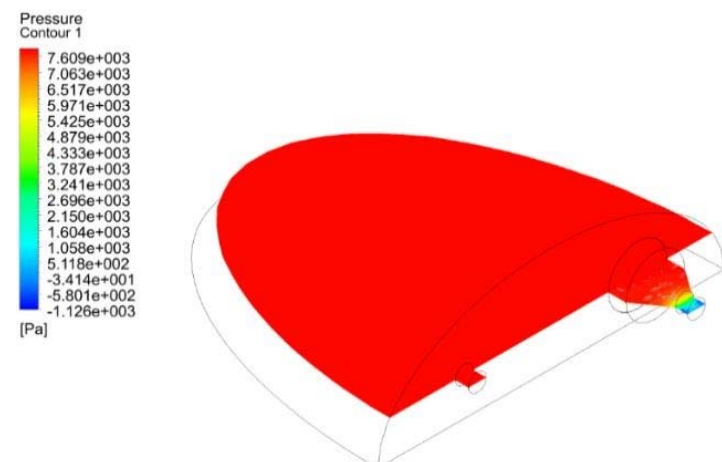

Fig. 8. Pressure distribution contour for foot to paver.
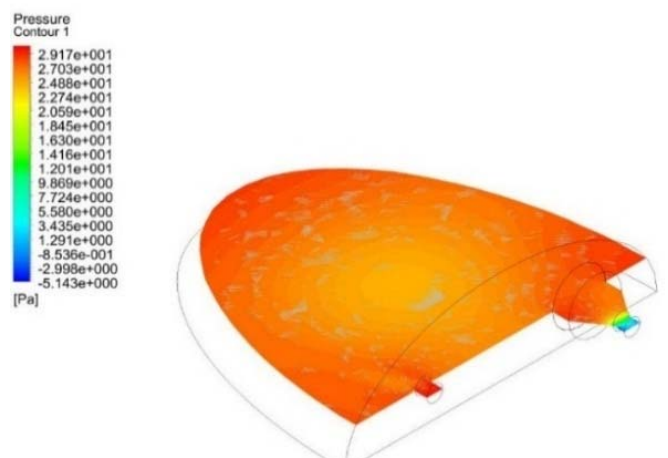

Fig. 9. Pressure distribution contour for paver to paver.

The power generating capability of the Quarter Ellipsoid bag fluid based energy harvester was examined by connecting the system with charge controller and random resistors as a load. Different resistive loads were kept constant for applied forces and the peak output power is shown in Fig. 10. The peak output voltage and power were measured for different load resistance ranging from $30 \Omega$ to $750 \Omega$ with an average force of $650-700 \mathrm{~N}$ is shown in Fig. 11. It was seen that the power increased to a peak of $1.4 \mathrm{~W}$ with load resistance of $390 \Omega$ and started to decrease thereafter. However, the current kept on decreasing whereas the voltage kept on increasing with the rising load resistance. 
Apparently, the relationship between pressure and output power are directly proportional for fluid based energy harvesting technique. A greater force applied to the paver will create significant amount of pressure which rotates the mini hydro generator effectively.

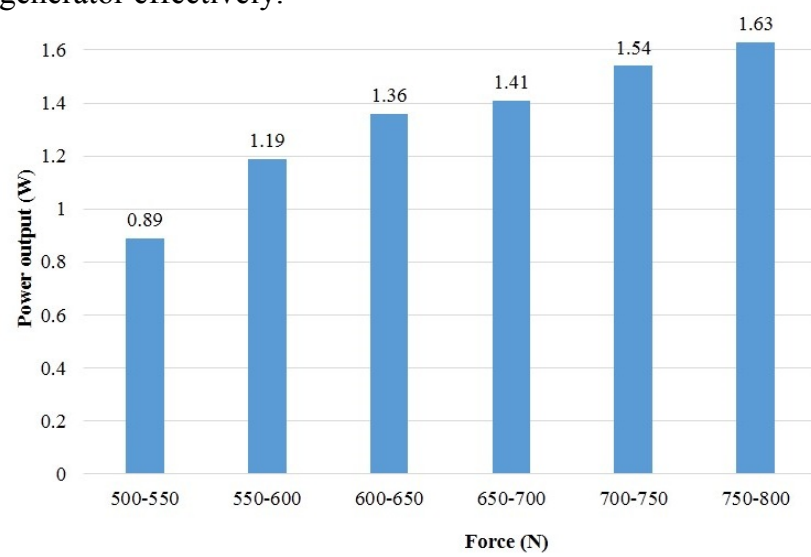

Fig. 10. Average power output with different applied force.

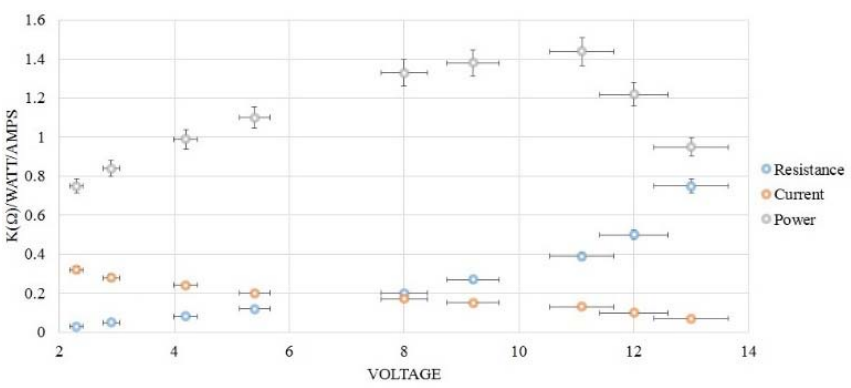

Fig. 11. Voltage, Current and Power output at different load resistance for Fluid Based Energy Harvesting System.

\section{CONCLUSION}

This research shows that a fluid-based energy harvesting paver using a mini hydro generator was able to produce $1.4 \mathrm{~J}$ of energy per step. The proposed system uses the human footstep to produce electrical energy for powering a low powered device. The vertical applied force pushes the water from the bag to rotate the turbine and produce an electrical energy. Design of the fluid bag design with an enclosed mini hydro generator was studied in this research. The pressure simulation on different fluid bag design was carried out and the best design was further analyzed experimentally to see the performance of the turbine with applied force on the paver and found that the quarter ellipsoid shaped one is the best performer which can produce upto $1.4 \mathrm{~J}$ per step.

\section{ACKNOWLEDGMENT}

The authors would like to acknowledgment The University of the South Pacific and School of Engineering and Physics for funding this research project and research team for completion of this project.

\section{REFERENCES}

[1] S. S. Chand, A. Iqbal, M. Cirrincione, F. R. Islam, K. A. Mamun and A. Kumar, "Identifying Energy Trends in Fiji Islands. In Smart Energy Grid Design for Island Countries," Springer, Cham, pp. 259-287, 2017.
[2] U. Zafar, T. U. Rashid, A. A. Khosa, M. S. Khalil and M. Rashid, "An overview of implemented renewable energy policy of Pakistan," Renewable and Sustainable Energy Reviews, vol. 82, pp.654-665, 2018.

[3] U. F. Evans, G. Umoh, N. O. James and O. Hilary, "Environmental Sustainability Through Exploitation of Alternative Energy Sources (AES) in Akwa Ibom State, Nigeria," American Journal of Environmental Science and Engineering, vol. 3, pp.17-21, 2019.

[4] F. R. Islam and K. A. Mamun, "Possibilities and Challenges of Implementing Renewable Energy in the Light of PESTLE \& SWOT Analyses for Island Countries," In Smart Energy Grid Design for Island Countries. Green Energy and Technology, F. Islam, K. Mamun, M. Amanullah, Eds, Springer: Berlin, Germany, pp. 1-19, 2017.

[5] S. P. Beeby, M. J Tudor and N. M White, "Energy harvesting vibration sources for microsystems applications," Measurement science and technology, vol. 17, p.R175, 2006.

[6] K. Tao, H. Yi, L. Tang, J. Wu, P. Wang, N. Wang, L. Hu, Y. Fu, J. Miao and H. Chang, "Piezoelectric $\mathrm{ZnO}$ thin films for 2DOF MEMS vibrational energy harvesting,"Surface and Coatings Technology, vol.359,pp.289295, 2019.

[7] I. Izadgoshasb, Y. Y. Lim, L. Tang, R.V. Padilla, Z. S. Tang and M. Sedighi,"Improving efficiency of piezoelectric based energy harvesting from human motions using double pendulum system," Energy Conversion and Management, vol. 184, pp.559-570, 2019.

[8] J. Liang, Y. Zhao and K. Zhao, "Synchronized triple bias-flip interface circuit for piezoelectric energy harvesting enhancement," IEEE Transactions on Power Electronics, vol. 34, pp.275-286, 2019.

[9] M. Mariello, F. Guido, V. M Mastronardi, M. T Todaro, D. Desmaële and De M. Vittorio, "Nanogenerators for harvesting mechanical energy conveyed by liquids," Nano Energy, vol. 57, pp.141-156, 2019.

[10] H. Vocca and F. Cottone, "Kinetic energy harvesting. In ICT-EnergyConcepts Towards Zero-Power Information and Communication Technology," Intech Open, 2014.

[11] M. A. Hannan, S. Mutashar, S. A. Samad and A. Hussain, "Energy harvesting for the implantable biomedical devices: issues and challenges," Biomedical Engineering Online, vol.13, p.79, 2014.

[12] K. Mamun, F. M. R. Islam, M. Cirrincione, S. P. Chandra, and R. N. Deo, "Foot steps waste energy harvesting system using hydro generator," Available online: http://repository.usp.ac.fj/10944/ (accessed on 9 March 2019).

[13] H. Fu, K. Cao, R. Xu, M. A. Bhouri, Martínez-Botas, R., S.G. Kim and E.M. Yeatman, "Footstep energy harvesting using heel strike-induced airflow for human activity sensing," In 2016 IEEE 13th International Conference on Wearable and Implantable Body Sensor Networks (BSN) IEEE, pp. 124-129, 2016

[14] R. S. Khurmi, "A Textbook of Hydraulics, Fluid Mechanics and Hydraulics Machines, S. Chand $\backslash \&$ Company Ltd, Ramnagar," New Delhi, Edition, p. 341, 2010.

[15] Z. L. Seow, S. T. Chen and N. B. Khairudin, "An investigation into energy generating tiles." Pavegen. 2011

[16] Y. M. Choi, M. Lee and Y. Jeon, "Wearable biomechanical energy harvesting technologies.” Energies, vol.10, no.10, p.1483, 2017.

[17] M. Liu, R. Lin, S. Zhou, Y. Yu, A. Ishida, M. McGrath, B. Kennedy, M. Hajj and L. Zuo, "Design, simulation and experiment of a novel high efficiency energy harvesting paver." Applied Energy, vol.212, pp.966975, 2018.

[18] R. Cross,"Standing, walking, running, and jumping on a force plate," American Journal of Physics, vol. 67, pp.304-309, 1999.

[19] A. Tongen and R. E. Wunderlich, "Biomechanics of running and walking," Mathematics and Sports, vol. 43, pp. 1-2, 2010.

[20] A. Chand, "Fluid based Energy Harvesting Paver APPENDIX 1." Google Drvie, Available online: https://drive.google.com/file/d/1g6i8vE2iwXT3uIKNG\kCSok47hbHS ERB/view?usp=sharing, pp. 1-12, 2019.

[21] A. Chand, "Simualtion of pressure contour distribustion," Google Drvie, Available

on. https://drive.google.com/file/d/1W8\RTN1DLVHIB79A0tAYTanbXjx f3BwX/view?usp=sharing, 2019. 